Metodi. I pazienti provenivano dai reparti di Pneumologia e Gastroenterologia del Policlinico Universitario di Catanzaro. Sono stati valutati i seguenti parametri: eosinofili (contaglobuli automatico), IgE, PCR, C3, C4 (tecnica nefelometrica), IgG anti Ascaris (ELISA), esame parassitologico delle feci (osservazione microscopica dopo tecnica di arricchimento con formalina/etere), Prick test.

Risultati. Tutti i pazienti presentavano una positività al Prick test e/o livelli elevati di IgE sieriche. Il $46 \%$ dei pazienti presentava, inoltre un valore elevato di eosinofili in campioni di sangue venoso. L'esame parassitologico delle feci è risultato negativo per la ricerca di uova e larve di elminti, mentre la ricerca delle IgG anti Ascaris era positiva nel 23\% dei campioni di siero esaminati. Una paziente inclusa nel nostro studio aveva recentemente eliminato una larva di A. lumbricoides mediante vomica. Tale paziente è risultata ripetutamente negativa alla diagnosi diretta ed indiretta per tale parassita. Conclusioni. I nostri dati indicano un'assenza di correlazione tra atopia e positività ai test diretti ed indiretti per la ricerca di A. lumbricoides. Si potrebbe pertanto suggerire una forma di protezione immunitaria in soggetti atopici nei confronti di infestazioni da geoelminti.

\section{ASSENZA DI CORRELAZIONETRA POSITIVITÀ PER IgG ANTI ASCARIS E VARIABILI INFIAMMATORIE ED IMMUNOLOGICHE}

\author{
Zangaro E.', Spiniello E.', Laratta C.', Maselli R. ${ }^{2}$, Piizzi C. ${ }^{2}$, \\ Giancotti A. ', Rametti L.A.', Doldo P.', Izzo M. ${ }^{3}$, Cosimo P. ${ }^{3}$, \\ Matera G.', Liberto M.C. ', Focà A.' \\ ' Cattedra di Microbiologia \\ ${ }^{2}$ Cattedra di Pneumologia \\ ${ }^{3}$ Cattedra di Gastroenterologia \\ Università "Magna Graecia" di Catanzaro, Catanzaro.
}

Introduzione. Studi epidemiologici hanno dimostrato una correlazione negativa tra atopia ed infestazione con Ascaris lumbricoides. L'atopia è stata definita come una condizione legata alla presenza di un test cutaneo positivo ad allergeni, o di IgE sieriche a concentrazione elevata (Cooper P.J. et al. J Infect Dis 2004;190:1338-46). Obiettivo del presente studio è stato di correlare i parametri relativi allo stato di atopia e/o di flogosi, con la presenza di indicatori diretti o indiretti di infestazione da Ascaris lumbricoides. 